\title{
Implementatie van een protocol gericht op de zorgketen voor patiënten met een Lumbosacraal Radiculair Syndroom
}

\author{
Margot Fleuren, ${ }^{1}$ Dirk Wijkel, ${ }^{2}$ Jos Breuer, ${ }^{3}$ Hans van den Hoogen, ${ }^{4}$ Theo Lankhorst, ${ }^{5}$ Koen Brakel ${ }^{6}$
}

\begin{abstract}
Volgens de NHG-standaard Lumbosacraal Radiculair Syndroom (vaak hernia genoemd) dient de huisarts de eerste zes weken een conservatief beleid te voeren. In de praktijk accepteren patiënten dit soms moeizaam. Onder andere omdat meer patiënten dan wenselijk volgens de NHG-standaard, worden doorverwezen, ontstaan lange toegangs- en doorlooptijden in het ziekenhuis: gemiddeld acht en veertien weken in 1998 in het St. Annaziekenhuis in Geldrop. Daarnaast is er geen goede afstemming tussen disciplines in de behandellijn. Daardoor worden enerzijds patiënten 'voortijdig' verwezen; anderzijds maken patiënten met een indicatie voor verwijzing een lange wachttijd door. De voorgestelde interventie betrof een wijziging van de logistiek in het ziekenhuis en begeleiding bij de invoering van een protocol: indien de huisarts de NHGstandaard volgde, garandeerde het ziekenhuis daarna versnelde toegang tot de neuroloog en een MRI. Naast uitgebreide voorlichting werden werkafspraken en een gezamenlijke patiëntenfolder gemaakt. Bij het project waren 98 huisartsen, 150 fysiotherapeuten, vier neurologen en zes radiologen betrokken. In het artikel beschrijven we de stappen die systematisch zijn doorlopen bij de invoering en de uitkomsten van het implementatieproces. De belangrijkste conclusie is dat systematische invoering van de NHG-standaard, dat wil zeggen ondersteuning van de eerste lijn in combinatie met een logistieke reorganisatie in het ziekenhuis, mogelijk is. Het aantal voortijdige verwijzingen was laag en de gemiddelde toegangs- en doorlooptijden in het ziekenhuis namen af.
\end{abstract}

Trefwoorden: zorgketen, standaarden, lumbosacraal radiculair syndroom, huisarts

\section{INLEIDING}

Afgaande op de verschenen richtlijnen over het beleid bij het lumbosacraal radiculair syndroom (LRS), in de volksmond hernia, bestaat er in de richtlijnen inhoudelijke consensus tussen de verschillende hierbij betrokken beroepsgroepen. ${ }^{1-4}$ Dit zijn huisartsen, fysiotherapeuten, neurologen, orthopeden en neurochirurgen. De eerste zes weken dient men volgens de richtlijnen, uitzonderingen daargelaten, gezien de meestal gunstige prognose een conservatief beleid te voeren. Voorlichting, pijnbestrijding en mobiliseren 'zodra het kan' zijn de pijlers van dit beleid. Indien na zes weken conservatief beleid nog steeds immobiliserende pijn bestaat kan een chirurgische ingreep worden overwogen. Het aantal nieuwe LRSpatiënten in de huisartspraktijk is negen per 1000

\footnotetext{
TNO Kwaliteit van Leven, Leiden

Coördinator Stichting THEMA, St. Anna Zorggroep, Geldrop

Neuroloog, St. Anna Zorggroep, Geldrop

${ }^{4}$ Huisarts, Asten

Fysiotherapeut, Asten

Radioloog, St. Anna Zorggroep, Geldrop
}

patiënten per jaar ${ }^{5}$ en de directe en indirecte kosten gerelateerd aan LRS zijn naar schatting 1,2 miljard Euro. ${ }^{3}$

Hoewel de richtlijnen eensluidend zijn, blijkt het beleid in praktijk moeilijk uitvoerbaar. Een belangrijke reden is dat de patiënt, die kampt met hevige pijn, het conservatieve beleid moeizaam accepteert. ${ }^{6}$ Patiënten ervaren de hevige pijn vaak als bedreigend en willen graag dat de huisarts hen doorstuurt ofwel 'iets doet'. Huisartsen geven aan onder deze druk vroegtijdig te verwijzen. ${ }^{7}$ Daarnaast is er geen goede afstemming tussen de mogelijk betrokken zorgverleners; de huisarts, de fysiotherapeut en de eventueel betrokken bedrijfsarts geven soms tegenstrijdige adviezen, bijvoorbeeld over de noodzaak van een Magnetic Resonance Imaging (MRI), verwijzing en/of operatie. Onder druk van het advies van andere zorgverleners verwijzen huisartsen eveneens patiënten voortijdig. ${ }^{7}$ Dit heeft zijn weerslag op de wachttijden voor het eerste consult met de neuroloog in het ziekenhuis. Een ander probleem is de logistieke afstemming in het ziekenhuis. Een patiënt is vaak gedwongen om een aantal weken wachttijd door te maken; 
bijvoorbeeld voor de eerste afspraak met de neuroloog, de MRI, een vervolgafspraak met de neuroloog en een eventuele operatie.

Huisartsen geven aan 'alvast meteen' te verwijzen, omdat de patiënt toch op een wachtlijst komt te staan. ${ }^{7}$ Patiënten bellen in de regel een afspraak bij de neuroloog niet af wanneer de LRS-klachten in de 'wachtperiode' verminderen. Vanuit het oogpunt van de juiste therapie op het juiste moment is dit een probleem. Neurologen ervaren bovenstaande voortijdige verwijzingen als een knelpunt. Zij geven aan patiënten te zien die eigenlijk niet verwezen hadden hoeven worden, ofwel omdat spontaan herstel is opgetreden ofwel omdat de neuroloog de consulttijd moet gebruiken om uit te leggen dat spontaan herstel afgewacht moet worden. ${ }^{7} \mathrm{Al}$ met al lijkt er voornamelijk sprake te zijn van een implementatieprobleem en geen medisch inhoudelijk probleem; de evidence is immers duidelijk en de richtlijnen zijn eensluidend.

In 1998 bedroeg in het St. Annaziekenhuis in Geldrop de gemiddelde toegangstijd voor een eerste consult met de neuroloog acht weken. ${ }^{8}$ De tijd tussen verwijzing door de huisarts en het consult waarin de neuroloog de definitieve diagnose stelde (doorlooptijd) bedroeg gemiddeld 14 weken. Vergeleken met de NHG-standaard LRS, ${ }^{1,6}$ was $25 \%$ van de door de huisarts verwezen LRS-patiënten volgens de neuroloog voortijdig binnen zes weken verwezen. ${ }^{8}$ De coördinator van Stichting THEMA (tweede auteur) besprak deze resultaten met huisartsen en specialisten en stelde de volgende interventie voor: Indien de huisarts de NHG-standaard volgt, garandeert het ziekenhuis daarna (indien nog nodig) versnelde toegang tot de neuroloog en een MRI. Hiertoe werd een LRS-protocol opgesteld. Het doel van ons project was dit LRS-protocol in de hele zorgketen in de regio Geldrop in te voeren. Het project vond plaats binnen het kwaliteitsprogramma District op Orde dat werd opgezet door de Orde van Medisch Specialisten voor de ontwikkeling en implementatie van transmurale zorgvernieuwingsprojecten. ${ }^{9}$ Het project werd als geslaagd beschouwd wanneer één jaar na invoering: a) het aantal voortijdig binnen zes weken verwezen patiënten met $50 \%$ was afgenomen en b) de toegangstijd tot de polikliniek was verminderd naar gemiddeld zeven dagen en de doorlooptijd naar gemiddeld drie weken. De vraagstellingen zijn:

- Lukt het huisartsen en fysiotherapeuten om volgens het protocol te werken en wat zijn mogelijke belemmeringen daarbij?
- Wat is een jaar na invoering van het protocol het aantal voortijdig binnen zes weken verwezen LRSpatiënten?

- Lukt het de betrokkenen in het ziekenhuis om een verkorte toegangs- en doorlooptijd te realiseren voor volgens protocol verwezen patiënten en op langere termijn te behouden?

\section{Methoden}

\section{Interventie}

In 2002 werd voor de regio een LRS-protocol opgesteld, aanvullend op de NHG-standaard. Een belangrijke aanvulling was dat indien de huisarts de NHGstandaard volgde, de patiënt bij onvoldoende effect van zes weken conservatief beleid versneld terecht kon bij de neuroloog en voor een MRI. De patiënt moest dan maximaal één week wachten voor het eerste consult bij de neuroloog en daarna nog maximaal twee weken voordat de definitieve diagnose bekend was. Hiertoe moest de interne logistiek in het ziekenhuis voor LRS-patienten aangepast worden: de neurologen en radiologen hielden hiervoor elke week een beperkt aantal plaatsen 'vrij'. Deze uren werden flexibel ingevuld en waren niet alleen gereserveerd voor de LRS-patiënten, maar voor alle 'spoed' gevallen. Per week werden tussen de drie en vijf plekken door LRS-patiënten ingevuld. Voor toegang tot de versnelde procedure diende de huisarts de patiënt bij verwijzing als 'LRS versneld trajectpatiënt' aan te melden. Wanneer de huisarts op reguliere wijze instuurde, volgde de patiënt het bestaande verwijstraject met bijbehorende wachttijden. Bij de directe invoering waren alle huisartsen $(n=98)$ en fysiotherapeuten (circa 150) in het adherentiegebied van het ziekenhuis betrokken en alle neurologen $(n=4)$ en radiologen $(n=6)$ in het ziekenhuis. Voor de (begeleiding van de) invoering werd een projectgroep opgericht bestaande uit de auteurs van dit artikel.

\section{Procesevalatie}

Het LRS-protocol werd systematisch ingevoerd volgens een implementatiemodel. ${ }^{10,11}$ Het uitgangspunt van dit implementatiemodel is dat in alle fasen in een innovatieproces (verspreiding, adoptie, implementatie en continuering) complicaties kunnen optreden. Wil de invoering succesvol zijn, dan is het van essentieel belang om voorafgaand aan de invoering na te gaan welke determinanten van de innovatie, ofwel belemmerende en bevorderende factoren, in de verschillende fasen van het innovatieproces een rol spelen. Dit is nodig om vervolgens invoerstrategieën te kunnen kiezen die aangrijpen op es- 
sentieel gebleken determinanten. De determinanten dienen onderzocht te worden op het niveau van de vernieuwing zelf, de toekomstige gebruiker, de organisatie en de bredere sociaal-politieke omgeving. ${ }^{10,11}$

Eerst besprak de projectgroep met alle neurologen, alle radiologen en het afsprakenbureau in het ziekenhuis wat men vond van de versnelde procedure en welke logistieke consequenties hieruit voortvloeien. De radiologen waren huiverig voor een grote toestroom van patiënten maar waren wel bereid het (verbeter)project met een beperkt aantal gereserveerde plaatsen aan te gaan. Omdat het aantal 'gereserveerde' plaatsen voor versnelde toegang tot de MRI en de neuroloog beperkt was, leverde dit logistiek gezien geen probleem op. Om de haalbaarheid van het werken met het protocol na te gaan vonden gemengde focusgroepsinterviews plaats met in totaal zes huisartsen en acht samenwerkende fysiotherapeuten over het concept-LRS-protocol.

Op basis van de uitkomsten van de focusgroepinterviews werden invoerstrategieën gerealiseerd. Het protocol en de versnelde toegang werden ingevoerd per 1 april 2002. De determinantenanalyse en invoerstrategieën vonden plaats tussen augustus 2000 en april 2002.

\section{Effectevaluatie}

Ter beantwoording van de tweede en derde vraagstelling werd een registratieonderzoek uitgevoerd met een voormeting (november 2001 tot april 2002) en een nameting (november 2002 tot april 2003). Om enig zicht te krijgen op de continuering van de effecten werd in de periode november 2003 tot april 2004 nogmaals de doorlooptijd in de polikliniek onderzocht.

- Voor het vaststellen van voortijdige verwijzingen bekeek één neuroloog uit de maatschap de statussen van alle LRS-patiënten die voor het eerst waren gezien gedurende de voormeting en nameting. De neuroloog registreerde de soort verwijzing (regulier of versneld volgens protocol; zie uitleg 'interventie'). Verder registreerde de neuroloog of de verwijzing terecht was: terecht na zes weken; terecht binnen zes weken vanwege complicaties; voortijdig binnen zes weken; onterecht ná zes weken vanwege bijvoorbeeld eerdere complicaties; regulier in plaats van versneld volgens protocol. Voor een terechte verwijzing binnen zes weken werden de criteria uit de NHG-standaard gehanteerd (figuur 1). Een onterechte verwijzing na zes weken werd beoordeeld op basis van de klinische inschatting van de neuroloog.

- De toegangstijd tot de polikliniek (tijd tussen verwijzing en eerste polikliniekbezoek) stelde de neuroloog vast op basis van de status van de patiënt.

- De doorlooptijd in de polikliniek (tijd tussen eerste polikliniekbezoek en het consult waarin de definitieve diagnose werd gesteld) werd berekend via het afsprakensysteem in combinatie met de registratie door de neuroloog. Opgeteld vormen de toegangstijd en doorlooptijd in de polikliniek de totale doorlooptijd.

- Het totaal aantal verwezen LRS-patiënten in de voormeting (januari tot april 2002) en de nameting (januari tot april 2003) werd bepaald op basis van het afspra- kensysteem in het ziekenhuis voor LRS-patiënten (DBC-code 1203).

Verschillen in gemiddelde toegangstijd en doorlooptijd tussen voor- en nameting werden via T-toetsen nagegaan waarbij tweezijdig werd getoetst en p-waarden van $\mathrm{p}<0,05$ beschouwd werden als statistisch significant.

\section{RESUltaten}

\section{Procesevaluatie}

Uit de focusgroepinterviews kwamen de volgende kritie-

ke determinanten naar voren:

- Het succes van de invoering van het protocol valt of staat met de afspraken die in de behandelketen gemaakt kunnen worden. Volgens de deelnemers zaten fysiotherapeuten, huisartsen en bedrijfsartsen niet altijd op één lijn qua beleid en voorlichting. Wanneer disciplines verschillende informatie verstrekken aan de patiënt, bijvoorbeeld over de noodzaak tot verwijzing, neemt de druk van patiënten op de huisarts toe. Daarnaast zeiden de deelnemers dat er geen duidelijke en eenduidige folder / brief met patiënteninformatie was ter ondersteuning van het beleid.

- Aangezien de gemiddelde toegangstijd tot de polikliniek lang was, verwezen huisartsen alvast bij het eerste of tweede consult zodat de patiënt niet veel later dan na zes weken conservatief beleid aan de beurt zou zijn. De versnelde procedure kwam hieraan tegemoet volgens de deelnemers.

- De deelnemers vonden de NHG-standaard op enkele punten onduidelijk. Niet duidelijk was wanneer de termijn van zes weken precies inging. Daarnaast vond men de opbouw van de medicatie bij pijnbestrijding te conservatief. Om te kunnen mobiliseren, moet een patiënt redelijk vrij van pijn zijn. Daarom werd voorgesteld eerder met morfine te starten.

- Vooral de fysiotherapeuten vonden het een omschakeling deze groep patiënten 'met de handen op de rug' te begeleiden. Zij gaven aan gewend te zijn om 'iets te doen'. Het gevaar is dat de patiënt daardoor een bevestiging krijgt dat een actief beleid zinvol is, aldus de deelnemers. Hetzelfde geldt voor het uitgebreid verrichten van diagnostische testen. Daarom werd het belangrijk gevonden om alle fysiotherapeuten bij de invoering van het protocol te betrekken.

Aansluitend bij bovenstaande determinanten en op suggestie van de deelnemers aan de focusgroepinterviews werden de volgende invoerstrategieën gerealiseerd:

- Bespreking van het concept LRS-protocol in een workshop met huisartsen en specialisten tijdens een regionaal congres van het Medisch Coördinerend Centrum THEMA

- Informatiebijeenkomst voor alle fysiotherapeuten uit de regio, gericht op adoptie van het LRS-protocol

- Uitbreiding van het LRS-protocol met werkafspraken voor huisartsen en fysiotherapeuten, onder andere wat betreft medicatiebeleid (figuur 1)

- Ontwikkeling van een gezamenlijke patiëntenfolder Rughernia die door de huisartsen, fysiotherapeuten en neurologen werd en wordt gebruikt 
Figuur 1 Samenvatting protocol voor LRS-patiënten voor het beleid van de huisarts en de fysiotherapeut

\section{Beleid huisarts}

Anamnese en lichamelijk onderzoek

- Anamnese en lichamelijk onderzoek conform NHG-Standaard LRS

- Overleg dienstdoende neuroloog bij (tevens criteria voor verwijzing binnen 6 weken): - cauda syndroom

- verdenking andere pathologie

- snelle progressieve uitval in m. quadriceps (L4), voetheffers ( $\left.L_{5}\right)$, kuitspier (S1)

- onhanteerbare thuissituatie

- hevig invaliderende pijn

Voorlichting

- Uitleg over LRS

- Benadrukken natuurlijk beloop en gunstige prognose

- bij 8 van de 10 patiënten nemen klachten in eerste 6 weken af

- natuurlijk herstel heeft voorkeur boven operatie

- rugklachten kunnen na herstel blijven bestaan, ook na operatie

- $80-90 \%$ is na 1 jaar goed hersteld

- Patiëntenfolder meegeven

Medicatie

- Bij hevige pijnklachten zwaardere pijnmedicatie: in stappen medicatie verhogen/opbouwen, zo nodig tot morfinomimetica of direct met morfinomimetica starten

Advisering

- Bedrust niet geïndiceerd

- Zoveel mogelijk in beweging blijven; voorzichtig bij houdingen/bewegingen die extreme pijnklachten veroorzaken

- Indien patiënt conservatief beleid afwijst en neurologisch onderzoek wenst, benadrukken dat:

- men meent niet te moeten opereren alvorens eerst 6 weken is afgewacht (of natuurlijk herstel optreedt)

- zie verder onder 'voorlichting'

Controles

- Na 1, 2 en 4 weken op pijnmedicatie en mobiliteit (ADL)

- Bij gunstig beloop na 6 weken beleid voortzetten op ADL, hervatting werk, sportactiviteiten

Inschakelen fysiotherapeut

- Zo nodig bij opbouw en hervatten oude activiteiten

Verwijzing LRS polikliniek

- Indien conservatief beleid niet resulteert in verwachte verbetering binnen 6 weken

- Indien patiënt dusdanig twijfelt aan juistheid beleid dat hij/zij daardoor niet het beleid kan volgen

- Aanmelden versnelde traject bij neuroloog en voor MRI

\section{Beleid fysiotherapeut}

Lichamelijk onderzoek

- Onderzoek van ADL-vaardigheden

- Bepalen belemmerende factoren bij uitvoering ADL-functies (onzekerheid, bewegingsangst)

- Vaststellen mobilisatiedoelen (ADL-vaardigheden)

Voorlichting

- Herhalen uitleg over LRS, beloop en prognose

- Bevestigen advisering huisarts over conservatief beleid

Begeleiding (tot 6 weken)

- Begeleiding bij verbetering ADL-vaardigheden

- Geleidelijk opbouwen van belasting

- Bij moeilijk te mobiliseren patiënten gebruik van krukken adviseren

- Frequentie consult in eerste week twee keer, daarna één keer per week (afhankelijk van ernst klachten, aard belemmeringen en leervermogen patiënt)

- Advisering bij hervatting werk en/of sportactiviteiten

Afstemming met huisarts

- Bij twijfel verloop en resultaten na 2 weken huisarts raadplegen

- Bij twijfel over verwezen patiënten met rugklachten en vermoeden van ontwikkeling van LRS huisarts raadplegen

- Schriftelijke terugkoppeling naar huisarts na 6 weken over mate van ADL-status en pijnklachten

- Artikelen in regionale pers over de behandeling van LRS

- Bezoek aan alle HAGRO's door de projectgroep voor uitleg en ondersteuning waarbij de huisartsen werden gevraagd samenwerkingsafspraken te maken met de fysiotherapeuten waarnaar men verwees

- Beschikbaarheid van de projectgroep als helpdesk gedurende het hele project.

- Regionale nascholingsbijeenkomst voor bedrijfsartsen Het volledige overzicht van determinanten en aansluitende strategieën is elders beschreven. ${ }^{7}$

\section{Effectevaluatie}

Het totaal aantal LRS-patiënten dat voor een eerste consult werd verwezen, veranderde niet tussen voormeting (144 patiënten) en nameting (145 patiënten). De neuroloog bekeek tijdens de voor- en nameting de statussen van respectievelijk 105 en 101 patiënten. Aan de hand van de gegevens uit het afsprakensysteem bekeek de neuroloog alsnog een deel van de 'gemiste' statussen. De neuroloog kon hierbij geen specifieke selectie vaststellen. Uit tabel 1 blijkt dat er geen verschil is tussen voor- en nameting wat betreft het aantal voortijdig verwezen patiënten binnen zes weken ( $6 \%$ versus $4 \%$ ) en het aantal terecht verwezen patiënten binnen zes weken ( $5 \%$ versus $7 \%)$. De neuroloog vond dat één patiënt in de nameting 
vrij laat was ingestuurd. Verder waren er 12 patiënten die na zes weken in aanmerking hadden kunnen komen voor het versnelde traject, maar door de huisarts regulier waren verwezen.

Uit tabel 2 blijkt dat zowel de gemiddelde toegangstijd als de gemiddelde doorlooptijd kleiner waren in de nameting voor de patiënten die versneld waren ingestuurd ten opzichte van de reguliere patiënten. Opgeteld nam daarmee ook de totale gemiddelde doorlooptijd af tot minder dan drie weken. Twee jaar na invoering van het protocol was de gemiddelde doorlooptijd nog steeds op hetzelfde niveau als bij de nameting: de gemiddelde doorlooptijd voor de patiënten via het versnelde traject $(n=47)$ bedroeg 9,8 $(s d=6,6)$ dagen en voor de overige patiënten $(\mathrm{n}=99) 28,5(\mathrm{sd}=16,9)$ dagen.

\section{DISCUSSIE}

Tijdens de nameting is het aantal voortijdig verwezen patiënten zeer gering (4\%). Een duidelijke daling vergeleken met de voormeting (6\%) blijkt echter niet aantoonbaar. Dit wordt waarschijnlijk veroorzaakt door de uitgebreide bespreking naar aanleiding van de onderzoeksresultaten uit $1998^{8}$ en de aandacht die het project heeft gekregen voorafgaande aan de invoering (determinantenanalyse en invoerstrategieën). Hierdoor heeft een deel van de huisartsen al een conservatiever beleid gevoerd conform het protocol. ${ }^{7}$

De gemiddelde toegangs- en doorlooptijden werden in het project voor de versneld traject patiënten sterk gereduceerd. Dit gold niet alleen voor de versneld traject patiënten; ook voor de 'overige' LRS-patiënten nam de gemiddelde toegangstijd af hoewel de daling onder de versneld traject patiënten beduidend hoger was. Dat in beide groepen een daling optrad zou kunnen duiden op een algemene daling van toegangstijden voor deze patiënten. Echter vergeleken met de toegangstijden in andere ziekenhuizen op dezelfde peildatum (1 augustus 2003; www.nvz-ziekenhuizen.nl) zijn de door ons gevonden tijden nog steeds korter. Bovendien bleek een jaar na afloop van het onderzoek de doorlooptijd in de polikliniek nog steeds gereduceerd en op hetzelfde niveau als bij de nameting.

Hoewel de uitkomsten als succesvol mogen worden beschouwd, blijven verbeteringen mogelijk. Zo zouden huisartsen in nog meer gevallen gebruik kunnen maken van de versnelde procedure op de polikliniek; ruim 10\% van de verwezen patiënten werd regulier ingestuurd terwijl ze voor het versnelde traject in aanmerking kwamen.

Bij het onderzoek zijn enkele kanttekeningen te plaatsen. Zo is niet met zekerheid vast te stellen of het beleid van de huisartsen meer dan voorheen volgens de bestaande richtlijnen verloopt. Dit komt omdat voorafgaande aan de voormeting al aandacht werd besteed aan het project. Verder hebben we geen gegevens van het aantal patiënten dat de huisarts consulteerde. Strikt genomen kunnen alleen valide uitspraken gedaan worden over het gedrag van huisartsen als er in de huisartspraktijk gemeten wordt. Er waren pragmatische redenen om toch alleen in het ziekenhuis te meten. In de eerste plaats is het meten in de huisartspraktijk door de lage incidentie van het LRS vrijwel onuitvoerbaar en zou een onevenredige onderzoeksinspanning vragen. In de tweede plaats betreft het een haalbaarheidsonderzoek van de invoering van het protocol. We beoogden niet om wetenschappelijk onomstotelijk vast te stellen dat er veranderd gedrag optrad.

Om het effect van het protocol goed te kunnen beoordelen was het beter geweest ook gegevens in een controleregio te verzamelen. Het budget liet dit helaas niet toe.

We weten niet of het conservatieve beleid tot een verschuiving in medische consumptie heeft geleid. Misschien hebben patiënten in de eerste zes weken nu vaker de huisarts of fysiotherapeut geconsulteerd. Er is niet onderzocht of de huisartsen in de regio Geldrop naar andere ziekenhuizen zijn gaan verwijzen. We hebben daar geen aanwijzing voor en de ratio hiervoor ontbreekt. Ook hebben we geen aanwijzingen dat het verwijsgedrag van huisartsen buiten de regio is veranderd. Alléén de huisartsen in het adherentiegebied van het St. Annaziekenhuis hadden toegang tot de versnelde procedure. Voor patiënten van huisartsen buiten het adherentiegebied golden de reguliere toegangstijden. Dit ter voorkoming van een toeloop van patiënten buiten de regio Geldrop.

Er is niet onderzocht of de verminderde toegangstijd voor de protocolpatiënten ten koste is gegaan van de wachttijden voor de andere patiënten. Dit lijkt echter niet aannemelijk. In de eerste plaats omdat het aantal gereserveerde plaatsen beperkt was. In de tweede plaats omdat er simpelweg langer werd doorgewerkt wanneer er voor een spreekuur meer patiënten waren aangemeld dan geplaatst zouden kunnen worden (mededeling neuroloog en radioloog).

Tabel 1 Beoordeling door neuroloog van verwijzingen door de huisarts tijdens de voormeting (november 2001 tot april 2002) en nameting (november 2002 tot april 2003) in aantallen

\begin{tabular}{|c|c|c|}
\hline & $\begin{array}{c}\text { Voormeting } \\
n=105\end{array}$ & $\begin{array}{c}\text { Nameting } \\
n=101\end{array}$ \\
\hline \multicolumn{3}{|l|}{ Terecht verwezen na 6 weken } \\
\hline - versneld traject: terecht & n.v.t. & 24 \\
\hline - regulier verwezen: terecht * & 94 & 53 \\
\hline - regulier verwezen: onterecht niet voor versneld traject aangemeld & n.v.t. & 12 \\
\hline Terecht verwezen binnen zes weken & 5 & 7 \\
\hline Voortijdig verwezen binnen 6 weken & 6 & 4 \\
\hline Ontrecht verwezen na 6 weken & - & 1 \\
\hline
\end{tabular}

* In de nameting zijn dit patiënten met langdurige klachten of een niet acuut recidief 
Tabel 2 Verschil in gemiddelde toegangstijd tot de polikliniek en gemiddelde doorlooptijd in de polikliniek tussen voor-en nameting, met 95\% betrouwbaarheidsintervallen en uitgesplitst naar versneld traject patiënten en de regulier verwezen patiënten (in dagen)

\begin{tabular}{lccc}
\hline & Voormeting & Nameting & Verschil (95\%-BI) \\
\hline Toegangstijd tot polikliniek & $18,4(\mathrm{n}=97)$ & $8,1(\mathrm{n}=98)^{\star}$ & $10,3(6,8-13,8)$ \\
- Patiënten via versneld traject & & $3,6(\mathrm{n}=35) \S$ & $7,0(4,2-9,9)$ \\
- Regulier verwezen patiënten & & $10,6(\mathrm{n}=63) \S$ & $1,0(-5,3-3,3)$ \\
Doorlooptijd & $23,5(\mathrm{n}=101)$ & $22,5(\mathrm{n}=96)$ & $18,4(\mathrm{n}=34) \dagger$ \\
- Patiënten via versneld traject & & $29,2(\mathrm{n}=62) \dagger$ & $13,1-24,2)$ \\
- Regulier verwezen patiënten & & & $18,8(13)$ \\
\hline
\end{tabular}

* T-toets, gemiddelde verschil tussen totale toegangstijd voor- en nameting significant: $t=-11,1, p<0,001$

$\S$ T-toets, gemiddelde verschil tussen versneld traject en overige patiënten significant: $t=-3,0, p<0,001$

$\uparrow$ T-toets, gemiddelde verschil tussen versneld traject en overige patiënten significant: $t=-7,8$ en $p<0,001$

Om de vergelijking tussen voor- en nameting zo zuiver mogelijk te houden beoordeelde één neuroloog alle verwijzingen. Hoewel de neuroloog expliciete criteria hanteerde zijn interpretatiefouten niet uit te sluiten. Als er een fout is gemaakt, dan is het een systematische fout. Het gaat vooral om de inschatting of een patiënt terecht binnen zes weken verwezen is. Wanneer de neuroloog dit niet goed kan beoordelen omdat achtergrondinformatie ontbreekt, zal de patiënt zijn gelabeld als 'onterecht verwezen binnen zes weken'. Voor de resultaten betekent dit dat deze in feite nog gunstiger uitvallen.

\section{CONCLUSIE}

Onze conclusie is dat een systematische invoering van de NHG-standaard in combinatie met een logistieke reorganisatie in het ziekenhuis haalbaar is. Verder bleek het mogelijk de gemiddelde toegangstijd voor patiënten die volgens protocol zijn verwezen, terug te brengen naar minder dan een week. De totale gemiddelde doorlooptijd kon worden teruggebracht naar minder dan drie weken en blijkt ook een jaar na afloop van het project behouden te zijn. Inmiddels is de hier beschreven werkwijze de reguliere werkwijze geworden in de regio Geldrop.

\section{Noot}

Financiering van dit project kwam tot stand via de Orde van Medisch Specialisten, District op Orde, projectnummer ZB.S.57.00.

\section{ABSTRACT}

Implementation of a Lumbosacral Radicular Syndrom guideline

We carried out a feasibility study on the implementation of a LRS-guideline (Lumbosacral Radicular Syndrom) in the Geldrop region, including one hospital and all 98 GPs and 150 physiotherapists referring to this hospital. We redesigned the care process in primary care and hospital for LRS-patients. A trade off was made between the medical specialists (neurologists, radiologists) and the GPs and physiotherapists. If the GP/physiotherapist adhered to the LRS-guideline (conservative management first six weeks), after six weeks, in turn, the hospital guaranteed a priority consultation with the neurologist and priority for MRI. A determinant analysis was carried out among GPs and physiotherapists and a multifaceted implementation strategy was developed that was tailored to the critical determinants. The results showed that the number of patients being referred within six weeks, with no indication, decreased. The waiting time for first consultation with the neurologist and the duration of the total diagnostic procedure also decreased.

Keywords: implementation, guidelines, transmural care, Lumbosacral Radicular Syndrom

\section{LITERATUUR}

1. Mens JMA, Chavannes AW, Koes BW et al. NHG-Standaard lumbosacraal radiculair syndroom. Huisarts Wet 2005;48: 171-8.

2. Centraal Begeleidingsorgaan voor de Intercollegiale Toetsing. Consensus het Lumbosacrale Radiculaire Syndroom. Utrecht: CBO, 1995

3. Gezondheidsraad. Diagnostiek en behandeling van het lumbosacraal radiculair syndroom. Publicatienummer 1999/18. Den Haag: Gezondheidsraad, 1999.

4. Bemmel R van, Boer J den, Hendriks HJM et al. KNGF-ontwerprichtlijn Postoperatief Lumbosacraal Radiculair Syndroom. Amersfoort: Koninklijk Nederlands Genootschap voor Fysiotherapie, 1999.

5. Linden MW van der, Westert GP, Bakker DH de, Schellevis FG. Tweede Nationale Studie naar ziekten en verrichtingen in de huisartspraktijk: klachten en aandoeningen in de bevolking en in de huisartspraktijk. Utrecht/Bilthoven: Nivel/RIVM, 2004.

6. Smeele IJM, Hoogen JMM van den, Mens JMA et al. NHGstandaard Lumbosacraal Radiculair Syndroom. Huisarts Wet 1998;39:78-89.

7. Fleuren MAH, Wijkel D. Ketenzorg voor patiënten met een Lumbosacraal Radiculair Syndroom. Samenwerking tussen huisartsen, fysiotherapeuten, neurologen, orthopeden en radiologen in de regio Geldrop. Leiden: TNO Preventie en Gezondheid, 2004.

8. Schouwenaars $S$. Stroomlijning door afstemming: het patiëntgericht herontwerpen van het transmurale zorgtraject van de patiëntengroep Hernia Nuclei Pulposi vanuit het St. Annaziekenhuis te Geldrop. Geldrop: St. Annaziekenhuis, 1998.

9. Slot HMJ, Boekman P, Klazinga NS. Medisch specialistische transmurale zorgvernieuwingsprojecten. Aard en omvang binnen het zorgvernieuwingsprogramma van de Orde van Medisch Specialisten 200-2004. Tijdschr Gezondheidswet 2005;83:494-9.

10. Fleuren MAH, Wiefferink CH, Paulusssen TGW. Determinants of innovation within health care organizations: Literature review and Delphi-study. Int J Qual Health Care 2004;16,10723. 
11. Fleuren MAH, Wiefferink CH, Paulussen TGWM. Determinanten van innovaties in gezondheidszorgorganisaties: systematische literatuurreview. Tijdschr Gezondheidswet 2006;84:160-7.

\section{CORRESPONDENTIEADRES}

Mw. dr. M.A.H.Fleuren, TNO Kwaliteit van Leven, Postbus 2215, 2301 CE Leiden, tel. 071-5181862, e-mail:

Margot.Fleuren@tno.nl

Voor publicatie aanvaard in juni 2007. 